

\title{
Solution Volume Effect of Photodegradation by 1-D WO 3 Nanorods via Microwave-Assisted Solvothermal Heating Under the UV Irradiation
}

\author{
Chia-Ting Lin and Teh-Hua Tsai*
}

Department of Chemical Engineering and Biotechnology, National Taipei University of Technology, Taipei 10608, Taiwan

*Corresponding author: Tel: +886 2 27712171; Ext. 2543; E-mail: t5679012@ntut.edu.tw

\begin{abstract}
The 1-D nanorods of $\mathrm{WO}_{3}$ was synthesized by solvothermal-assisted microwave system. These nanorods was employed as photocatalysts in the photodecomposition reaction of methyl orange under the UV light. The powder was characterized by XRD, SEM and TEM. UVVisible diffuse reflection spectroscopy was used to measure the degradation efficiency. Different total solution volumes ranging between 400-1000 mL were responsible for the change in organic pollutants' photocatalysis efficiency. Furthermore, the effect of changing the concentration of methyl orange from 100-400 ppm was also studied in the context of large solution volume. The results suggested that apparent pseudo-first-order homogeneous reaction model can be used for describing the kinetic behaviour and higher photocatalytic activities induced through large solution volumes; $\mathrm{k}_{\text {app }}$ is $5.34 \times 10^{-2} \mathrm{~min}^{-1}$ for $250 \mathrm{ppm}$ catalyst at $800 \mathrm{~mL}$ methyl orange solution. In addition, the photocatalytic activity of $\mathrm{WO}_{3}$ nanorods was 3.6 times higher than that of commercial $\mathrm{P}_{2} 5 \mathrm{TiO}_{2}$ powder.
\end{abstract}

Key Words: $\mathrm{WO}_{3}$, Photodegradation, Solution volume, Nanorods.

\section{INTRODUCTION}

The industrial revolution led to an increase in organic pollutants in wastewater, thereby causing several environmental problems. The textile industries manufacturing dyes for the bulk have caused an exponential increase in organic pollutants in wastewater. In recent times, several research studies have recommended different methods of purifying wastewater contaminated with dyes. In general, dye is removed from wastewater using different techniques, such as physical adsorption, biological and chemical treatment ${ }^{1-6}$. However, these purification processes have two major drawbacks i.e., secondary pollution and energy waste. In comparison, advanced oxidation processes (AOPs) are more environmentally friendly. In addition, AOPs effectively remove dye from wastewater by initiating the reaction of photocatalysis ${ }^{7,8}$. The common photocatalytic reaction involves the formation of hydroxyl free radicals. In general, the photogenerated electrons of the conduction band and electron holes of the valence-band are involved in this charge transfer reaction. In photocatalysis reaction, hydroxyl free radicals are produced as the excited charge gets transferred to the surface of the semiconducting photocatalyst ${ }^{9,10}$. Nano-titanium dioxide $\left(\right.$ nano- $\mathrm{TiO}_{2}$ ) is the most commonly used semiconductor photocatalyst in cleaning procedures. Titanium dioxide is available at economic prices ${ }^{11-13}$. However, tungsten trioxide $\left(\mathrm{WO}_{3}\right)$ has a band gap of 2.4-2.7
$\mathrm{eV}$, which is $0.5 \mathrm{eV}$ narrower than that of $\mathrm{TiO}_{2}(3.2 \mathrm{eV})$. A narrow band gap facilitates an easier separation of electron holes $^{14}$. Due to excellent photostability in acidic medium, tungsten trioxide $\left(\mathrm{WO}_{3}\right)$ shows higher photocatalytic effect under acidic environment ${ }^{15}$. In general, the factors governing the efficiency of a catalyst include composition, size, lattice structure, surface acidity and surface area. Catalyst composition and specific surface area are the most important factors governing the efficiency of a catalyst, because catalyst composition affects the lattice structure, surface acidity and phase composition of catalysts, while specific surface area is related to porosity, crystal size and particle size. The recently developed catalyst has nanostructure and high specific surface area. Therefore, the novel catalyst has higher photocatalytic efficiency ${ }^{16}$. It is postulated that the photolysis efficiency of nanorods is greater than that of spherical catalysts. Such kind of photocatalytic nanorods are characterized with large aspect ratios: a factor which facilitates sedimentation to enable easier separation of the catalyst from solution ${ }^{17}$.

About $200 \mathrm{~mL}$ of dye solution was used in general photodecomposition studies. These studies do not discuss how catalytic efficiency is affected with the change in volume. In research studies of photolysis, the solution volume is usually does not exceed $200 \mathrm{~mL}$ and the effect of volume change on photocatalytic efficiency is not discussed extensively. In addition, the concentration of the target pollutant is usually not set at 
high levels. But, research studies should incorporate target pollutants at high concentration as this will provide invaluable insight of photocatalysis of a large number of organic pollutions with high concentrations. To maintain cost-effective conditions in a research study, optimum decolourization conditions have been suggested.

Microwave technology has been extensively used in chemical synthesis and analysis. In this technique, microwave energy is used for rapid heating. Microwave energy has been successfully used for effective temperature control in chemical analysis and synthesis. Microwave energy is conducive in solvothermal method. Some of the advantages of employing microwave-assisted solvothermal method include heating throughout the media, fast reaction, high yield, excellent reproducibility, narrow particle distribution, high purity and efficient energy transformation ${ }^{18-20}$.

In present work, we have employed the microwave synthetic approach based on solvothermal method. This technique leads to the formation of 1-D $\mathrm{WO}_{3}$ nanorods: novel photocatalysts. Under irradiation of UV light, the photocatalytic activities of $\mathrm{WO}_{3}$ were evaluated using methyl orange (MO) as the model contaminant. In this experiment, our main objective was to study the effects of solution volume and high initial dye concentration on photocatalytic activities. In addition, $\mathrm{P} 25 \mathrm{TiO}_{2}$ was used as a photocatalyst under identical conditions. In this case, the anatase and rutile ratio of the photcatalyst was maintained at 80:20. This was done to investigate and compare the photocatalytic efficiency of $\mathrm{WO}_{3}$ nanorods and commercial $\mathrm{TiO}_{2}$. In order to understand the properties of the photocatalyst, characterization of the photocatalyst was performed using three different optical techniques: transmission electron microscopy (TEM), X-ray diffraction (XRD) and scanning electron microscope (SEM).

\section{EXPERIMENTAL}

In this experiment, $\mathrm{WCl}_{6}, \mathrm{H}_{2} \mathrm{O}_{2}$ and methyl orange (MO) reagents of analytical purity were used. These reagents were obtained from Aldrich in United States of America. These reagents were used without any further purification. PEG20000 and Degussa P25 $\mathrm{TiO}_{2}$ were supplied from (BDH, USA) and (Degussa, Germany), respectively.

Preparation of catalyst: $\mathrm{WCl}_{6}$ was used as the precursor material in this study. The microwave solvothermal system was used for synthesis. The synthesis process was performed in a generated device (Multiwave 3000, Anton Paar). The syntheses were carried out in double-walled digestion vessels, having an inner liner and cover made up of Teflon PFA. These digestion vessels were protected with an outer high strength ceramic vessel. $0.05 \mathrm{M}$ of $\mathrm{WCl}_{6}$ was dissolved in $100 \mathrm{~mL}$ of ethanol solution containing $0.3 \mathrm{~g}$ of the dispersant PEG 20000. The mixture was placed in the microwave solvothermal system and the syntheses process was executed at $200{ }^{\circ} \mathrm{C}$ for $15 \mathrm{~min}$. All the reaction temperatures were attained within $3 \mathrm{~min}$. A large amount of yellow precipitate was produced in this reaction. After cooling to room temperature, the precipitate was subjected to centrifugation. Thereafter, the precipitate was sequentially washed with a series of solvents, that is, distilled water, absolute ethanol and acetone. Finally, the washed precipitate was airdried at $65^{\circ} \mathrm{C}$ for $24 \mathrm{~h}$.
Characterization of catalyst: X-Ray diffraction (XRD) measurements were carried out at room temperature. To conduct these measurements, PANalytical X'pert PRO X-ray powder diffractometer was used along with $\mathrm{CuK}_{\alpha}(45 \mathrm{kV}, 40$ $\mathrm{mA}$ ) radiation. The scanning speed was fixed at $0.5 \%$. The structure and morphology of the as-synthesized and thermally processed $\mathrm{WO}_{3}$ products were characterized using a field emission scanning electron microscope (SEM). The particle size and morphology of tungsten oxide nanorods were determined using a Hitachi model H-7500 transmission electron microscope (TEM) and a tungsten filament. During this process, the accelerating voltage was fixed at $120 \mathrm{kV}$.

Photocatalytic activities of solution volume effect: While analyzing the degradation of methyl orange system, the photocatalytic performance of $\mathrm{WO}_{3}$ nanorods was evaluated. In a typical reaction, $250 \mathrm{ppm}$ of the photocatalyst was suspended in $50 \mathrm{ppm}$ of aqueous solution of methyl orange. Different volumes of the methyl orange aqueous solutions were used in this process, but the concentration was maintained intact. These different aliquots were transferred into the reactor and agitated for $0.5 \mathrm{~h}$. Thus, methyl orange particles were uniformly distributed on the surface of the catalyst. The photocatalytic degradation was carried out in a photocatalytic reactor. The photocatalytic reactor consists of two parts: (i) $1 \mathrm{~L}$ quartz cell with a circulating water jack and (ii) $15 \mathrm{~W}$ low-pressure mercury lamp placed inside the quartz cell. The maximum emission of this mercury lamp occurred at $306 \mathrm{~nm}$. In this case, the reaction temperature was always maintained at room temperature with the help of a circulating water jack. During irradiation and stirring, $c a$. $1 \mathrm{~mL}$ suspension was taken from the reaction cell at fixed time intervals. After centrifugation, these aliquots were used for the subsequent methyl orange concentration analysis. The photocatalytic degradation process was monitored using a UV-visible spectrophotometer (UNICAM UV 500). The absorbance of methyl orange was measured at $465 \mathrm{~nm}$ using the UV-visible spectrophotomer. The photodegradation efficiency of methyl orange was defined as follows:

Photodegradation efficiency $(\%)$

$$
=\frac{[\mathrm{MO}]_{0}-[\mathrm{MO}]_{\mathrm{t}}}{[\mathrm{MO}]_{0}} \times 100 \%
$$

where $[\mathrm{MO}]_{0}$ is the initial concentration of methyl orange and $[\mathrm{MO}]_{\mathrm{t}}$ is the concentration of methyl orange at certain reaction time $\mathrm{t}$ ( $\mathrm{min}$ ).

Photocatalytic activities of high concentration of dye: Experimental procedures are as follows: $250 \mathrm{ppm}$ of $\mathrm{WO}_{3}$ powder catalyst was dispersed in $800 \mathrm{~mL}$ of aqueous solutions of methyl orange with different concentrations. In this procedure, dispersion was carried out in 100, 200 and 400 ppm aqueous solutions of methyl orange. These dispersion reactions were performed at room temperature. The same condition was applied to irradiate catalysts. During irradiation of UV, $1 \mathrm{~mL}$ of the suspension was taken from the reaction suspension and centrifuged at $5000 \mathrm{rpm}$ for $0.5 \mathrm{~h}$. Thereafter, UV-visible spectrophotometer was used to measure the intensity of the centrifuged solution at $465 \mathrm{~nm}$.

Photocatalytic activities of commercial $\mathrm{TiO}_{2}$ (P25): Solutions containing $250 \mathrm{ppm}$ and $750 \mathrm{ppm}$ of $\mathrm{P}_{25 \mathrm{TiO}_{2} \text { were }}$ 
used as photocatalyst. These two solutions were dispersed in $800 \mathrm{~mL}$ of $50 \mathrm{ppm}$ methyl orange aqueous solution, respectively. Then, the $\mathrm{TiO}_{2}$ photocatalyst was replaced by $\mathrm{WO}_{3}$ and the experimental procedure was repeated under identical conditions. UV-visible spectrophotometer was used to measure photocatalytic activities.

\section{RESULTS AND DISCUSSION}

Characterization of 1-D $\mathrm{WO}_{3}$ photocatalysts: In order to confirm the crystalline structure of $\mathrm{WO}_{3}$ nanorods, powder XRD study was carried out. Fig. 1 shows the XRD patterns of fresh 1-D $\mathrm{WO}_{3}$ photocatalysts. The XRD patterns reveal that WO3 substrate has orthorhombic crystal (JCPDS No. 201324). Microwave-assisted solvothermal heating could successfully carry out the synthesis of $\mathrm{WO}_{3}$. This indicates that the nanorods grow along the [001] direction. All diffraction peaks are assigned to the well-know orthorhombic structures of $\mathrm{WO}_{3}$, wherein $\mathrm{a}=0.7384 \mathrm{~nm}, \mathrm{~b}=0.7512 \mathrm{~nm}, \mathrm{c}=0.3846$ nm (JCPDS No. 20-1324). No extraneous diffraction peaks were found in the XRD pattern. The result indicates that orthorhombic $\mathrm{WO}_{3}$ nanorods could be obtained by the microwaveinduced solvothermal process.

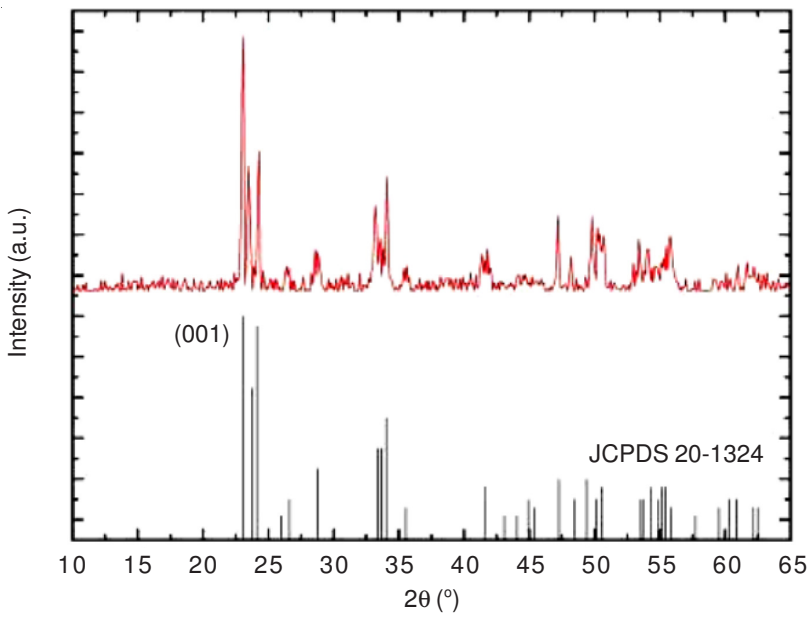

Fig. 1. X-Ray diffraction patterns of $\mathrm{WO}_{3}$ nanorods

The morphology of $\mathrm{WO}_{3}$ nanorods was characterized by SEM and the results were displayed in Fig. 2. The diameter of nanorods was $c a .80 \mathrm{~nm}$, while the nanorods were $c a .2 \mu \mathrm{m}$ in length. The highest aspect ratio of nanorods was more than 30, which explained their uniform size distribution. High aspect ratio facilitated sedimentation and led to easier separation of catalyst from solution. This property enabled the repeated use of the novel photocatalyst.

Fig. 3 shows the TEM image of the $\mathrm{WO}_{3}$ nanorods. Based on the findings of TEM investigation technique, the measured mean diameter of nanorods was reported to be $c a .80 \mathrm{~nm}$. The length of nanorods was to the tune of several microns, which was detected by the SEM images. Therefore, the nanorods exhibited a high aspect ratio that was greater than 30 . This result agreed with the SEM measurement.

Solution volume effect of photocatalytic activities of 1-D WO 3 nanorods: Basically, we have encountered a heterogeneous photocatalytic process that can be explained in terms of two elementary mechanisms: (1) oxidation of the organic

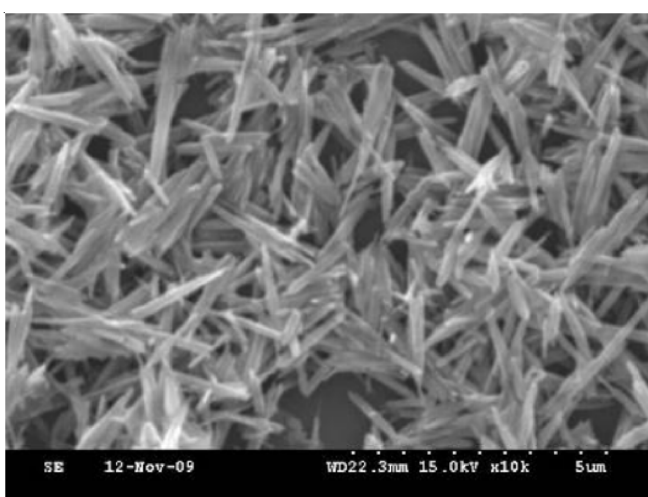

Fig. 2. SEM images of $\mathrm{WO}_{3}$ nanorods

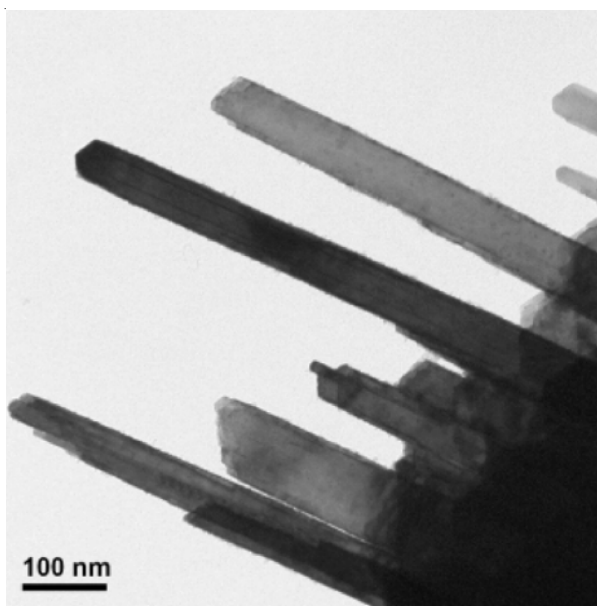

Fig. 3. TEM images of $\mathrm{WO}_{3}$ nanorods

dyes through the successive attacks of hydroxyl radical $\left(\mathrm{HO}^{\circ}\right)$; (2) direct reaction of the organic dyes with photogenerated holes through a process that resembles the photo-Kolbe reaction $^{21}$. In the first reaction mechanism, the dye molecules and the other oxygen containing species get adsorbed in neighboring sites. Oxygen is distributed on the photocatalytic surface and trapped electrons, leading to the formation of superoxide radical $\left(\mathrm{O}^{2-}\right)^{22}$. In summary, the photodegradation mechanism can be described through eqn. 2-6. However, the $\mathrm{OH}$ radical is primarily formed from the adsorbed $\mathrm{OH}^{-}$and $\mathrm{H}_{2} \mathrm{O}$ molecules, since electrons are donated to the photogenerated holes.

$$
\begin{gathered}
\mathrm{WO}_{3}+\mathrm{hv} \rightarrow \mathrm{WO}_{3}+\mathrm{e}_{\mathrm{CB}}^{-}+\mathrm{h}_{\mathrm{VB}}^{+} \\
\mathrm{h}_{\mathrm{VB}}^{+}+\mathrm{OH}^{-} \rightarrow \mathrm{OH}^{\bullet} \\
\mathrm{h}_{\mathrm{VB}}^{+}+\mathrm{H}_{2} \mathrm{O} \rightarrow \mathrm{OH}^{\bullet}+\mathrm{H}^{+} \\
\mathrm{e}_{\mathrm{CB}}^{-}+\mathrm{O}_{2} \rightarrow \mathrm{O}_{2}^{-} \\
\mathrm{e}_{\mathrm{CB}}^{-}+\mathrm{h}_{\mathrm{VB}}^{+} \rightarrow \text { Heat }
\end{gathered}
$$

In the presence of $1-\mathrm{D}_{3}$ nanorods, the photodegradation of methyl orange with different solution volumes was measured. The results are shown in Fig. 4. Table-1 shows the pseudo-first-order rate constant kapp for the photocatalytic degradation reaction of methyl orange at different total solution volumes. As shown in eqn. 7, the photodegradation reaction of methyl orange was proportional to the solution volume and was based on first-order kinetics: 


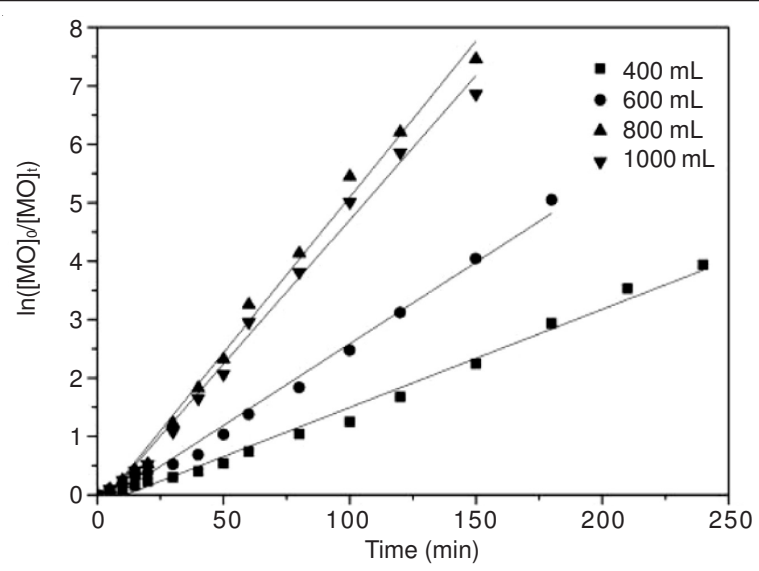

Fig. 4. Kinetics of methyl orange photodegradation (linear transform ln $\left(\mathrm{MO}_{0} / \mathrm{MO}_{\mathrm{t}}\right)$ versus $\left.(\mathrm{t})\right)$ in photocatalytic experiments using $\mathrm{WO}_{3}$ and different solution volume

\begin{tabular}{|c|c|c|}
\hline \multicolumn{3}{|c|}{$\begin{array}{c}\text { TABLE-1 } \\
\text { EFFECT OF DIFFERENT SOLUTION VOLUMES OF } \\
\text { METHYL ORANGE ON THE RATE CONSTANT } \\
\mathrm{k}_{\text {app }} \text { OF PHOTODEGRADATION }\end{array}$} \\
\hline Solution volume $(\mathrm{mL})$ & $\mathrm{k}_{\mathrm{app}}(465 \mathrm{~nm})$ & $\mathrm{R}^{2}$ \\
\hline 400 & $1.68 \times 10^{-2}$ & 0.98 \\
\hline 600 & $2.78 \times 10^{-2}$ & 0.99 \\
\hline 800 & $5.34 \times 10^{-2}$ & 0.99 \\
\hline 1000 & $4.67 \times 10^{-2}$ & 0.99 \\
\hline
\end{tabular}

$$
\ln \frac{[\mathrm{MO}]_{\mathrm{t}}}{[\mathrm{MO}]_{0}}=-\mathrm{k}_{\mathrm{app}} \mathrm{t}
$$

where $[\mathrm{MO}]_{\mathrm{t}}$ and $[\mathrm{MO}]_{0}$ are the concentration of methyl orange at time $t$ and initially, respectively. $\mathrm{k}_{\mathrm{app}}$ is the apparent pseudofirst-order rate constant.

As the solution volume increased, photocatalytic activity increased significantly. This activity tends to become steady when the solution volume is increased to $800 \mathrm{~mL}$. Thus, the optimal photocatalytic activity was $5.34 \times 10^{-2} \mathrm{~min}^{-1}$ at a solution volume of $800 \mathrm{~mL}$. Compared with photocatalytic activity at $400 \mathrm{~mL}\left(1.68 \times 10^{-2} \mathrm{~min}^{-1}\right)$ the optimal photocatalytic activity was 3.2 times larger at a solution volume of $800 \mathrm{~mL}$. Average $\mathrm{k}_{\text {app }}$ varied about $2.5 \times 10^{-2}-2.17 \times 10^{-3}$ when modified $\mathrm{TiO}_{2}$ was employed as the photocatalyst in place of the commonly used photocatalyst in the literature ${ }^{23,24}$. In case of modified $\mathrm{TiO}_{2}$, this range of values is much smaller than the $\mathrm{WO}_{3}$ nanorods mean. In summary, the optimum efficiency of $\mathrm{WO}_{3}$ nanorods was higher than that of modified $\mathrm{TiO}_{2}$.

The solution volume effect observed on the reaction rate is quite significant. This has been attributed to light intensity distribution in heterogenous photocatalytic reactors. In this reaction, the dispersion effect of UV irradiation increases with an increase in solution volume. However, when the solution volume is more than $800 \mathrm{~mL}$, the stirring effect decreases greatly, resulting in an uneven mixture of photocatalyst and methyl orange molecules. Thus, the photodegradation efficiency gets reduced $^{25}$. But, radiation transport equation (RTE) was mainly devised to explain concepts of wall reflectivity and catalyst loading. Radiation transport equation helped in simulating the model of photocatalysis. Radiation transport equation was not devised for a detailed discussion elaborating the impact of solution total volume. Furthermore, we also performed a blank experiment under identical conditions without using any photocatalyst. The blank experiment was performed in order to prove that the absorption of methyl orange dye at $306 \mathrm{~nm}$ did not occur as a result of the direct photocatalysis by UV. The experimental results indicate that the observed photodegradation could not be found after a long period of time. In other words, methyl orange does not direct photolysis and produces experimental error.

Changing concentration of methyl orange at high solution volume: Here, solution volume effect is investigated in dyes that are present in high concentration in the sample. After considering the experimental conditions, we selected the solution volume as $800 \mathrm{~mL}$. The methyl orange concentration varied from 100-400 ppm in this experiment. The best photodegradation was obtained at $100 \mathrm{ppm}$ in the presence of $\mathrm{WO}_{3}$ nanorods that functioned as photocatalysts (Fig. 5 and Table-2). The photodegradation efficiency was increased as the concentration of methyl orange was decreased. This finding was a complete contrast to the previous results, which suggested that the photodegradation efficiency of some organic pollutants increases with a higher initial concentration ${ }^{26}$. This anomaly is attributed to the UV light screening effect of the dye. At higher concentrations of methyl orange dye, some significant amount of UV may be absorbed by methyl orange molecules. As a consequence, high methyl orange concentration proves to be a barrier in the energy absorption by $\mathrm{WO}_{3}$. Thus, the photocatalytic activity of $\mathrm{WO}_{3}$ also witnesses a decline ${ }^{27}$. But, even as UV light screening effect hampers the efficiency of photocatalytic activity, $k_{\text {app }}$ value did not fall below that of modified $\mathrm{TiO}_{2}$. Although the UV light screening effect reduced the efficiency kapp, the solution volume effect still caused a substantial increase in efficiency $\left(\mathrm{k}_{\mathrm{app}}\right)$.

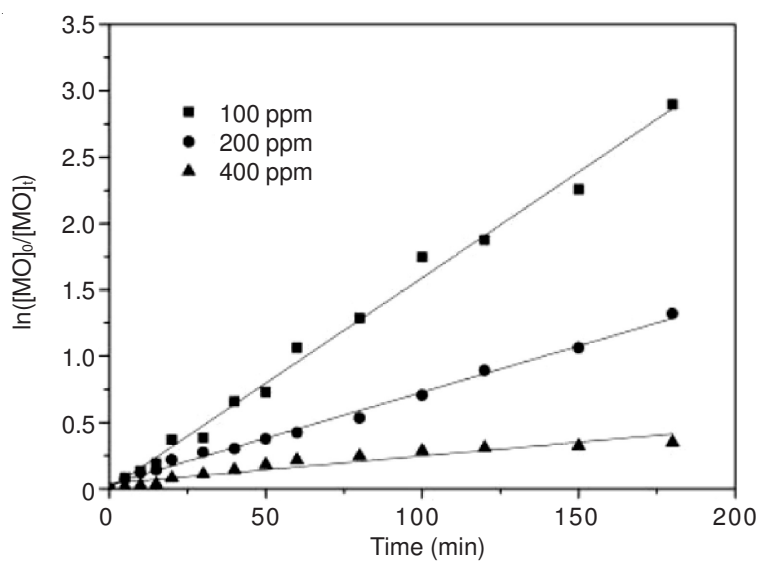

Fig. 5. Kinetics of methyl orange photodegradation (linear transform $\ln \left(\mathrm{MO}_{0} / \mathrm{MO}_{\mathrm{t}}\right)$ versus $\left.(\mathrm{t})\right)$ in photocatalytic experiments using $\mathrm{WO}_{3}$ and different initial concentration of methyl orange

TABLE-2

EFFECT OF DIFFERENT INITIAL CONCENTRATIONS OF METHYL ORANGE ON THE RATE CONSTANT $\mathrm{k}_{\mathrm{app}}$ OF PHOTODEGRADATION

\begin{tabular}{ccc}
\hline $\begin{array}{c}\text { Methyl orange } \\
\text { concentration }(\mathrm{ppm})\end{array}$ & $\mathrm{k}_{\mathrm{app}}(465 \mathrm{~nm})$ & $\mathrm{R}^{2}$ \\
\hline 100 & $1.59 \times 10^{-2}$ & 0.99 \\
200 & $6.95 \times 10^{-3}$ & 0.99 \\
400 & $2.08 \times 10^{-3}$ & 0.90 \\
\hline
\end{tabular}


Photocatalytic activities of P25: Fig. 6 shows photodegradation of methyl orange as function of photocatalyst concentration base. Apparently, the reaction follows the pseudo-first-order kinetics. Table-3 displays photocatalytic activities $\left(\mathrm{k}_{\text {app }}\right)$ of commercial $\mathrm{P} 25 \mathrm{TiO}_{2}$ and $\mathrm{WO}_{3}$ nanorods. At concentrations of 250 and $750 \mathrm{ppm}$, both 1-D $\mathrm{WO}_{3}$ nanorods were better than commercial P25 $\mathrm{TiO}_{2}$ as their photocatalyst efficiency was enhanced twice. Photocatalyst concentration is one of critical parameters that are associated with the photodegradation efficiency of dyes. The photodegradation efficiency of methyl orange was not enhanced even with an increasing amount of catalyst. The highest $\mathrm{k}_{\text {app }}$ of 5.31 $\times 10^{-2}$ and $1.44 \times 10^{-2} \mathrm{~min}^{-1}$ was obtained with $250 \mathrm{ppm}$ concentrations of $\mathrm{WO}_{3}$ and $\mathrm{TiO}_{2}$, respectively. Higher photocatalyst content implies that more active sites are available for absorbing much more photons. However, excessive photocatalyst does not display distinctively positive effect on photodegradation of methyl orange. This has been attributed to factors, such as scattering of light by catalyst and the reduction in the penetration of $\operatorname{light}^{28}$.

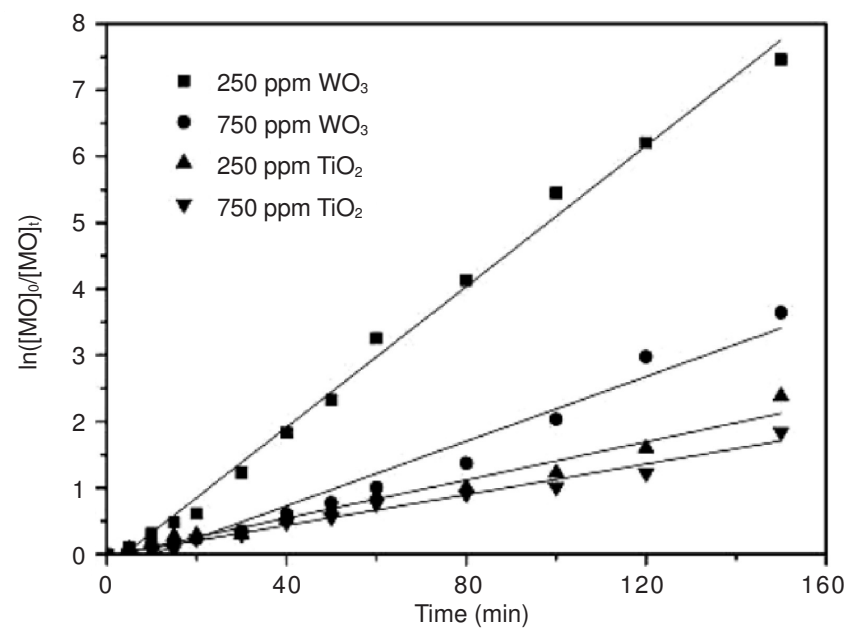

Fig. 6. Kinetics of methyl orange photodegradation (linear transform $\ln \left(\mathrm{MO}_{0} / \mathrm{MO}_{\mathrm{t}}\right)$ versus $\left.(\mathrm{t})\right)$ in photocatalytic experiments using $\mathrm{WO}_{3}$ and $\mathrm{TiO}_{2}$ for different concentration of photocatalyst

\section{TABLE-3}

EFFECT OF DIFFERENT PHOTOCATALYSTS ON THE RATE CONSTANT $k_{\text {app }}$ OF PHOTODEGRADATION

\begin{tabular}{ccc}
\hline Photocatalyst $(\mathrm{ppm})$ & $\mathrm{k}_{\text {app }}(465 \mathrm{~nm})$ & $\mathrm{R}^{2}$ \\
\hline $250 \mathrm{WO}_{3}$ & $5.31 \times 10^{-2}$ & 0.99 \\
$750 \mathrm{WO}_{3}$ & $2.44 \times 10^{-2}$ & 0.97 \\
$250 \mathrm{TiO}_{2}$ & $1.44 \times 10^{-2}$ & 0.97 \\
$750 \mathrm{TiO}_{2}$ & $1.16 \times 10^{-2}$ & 0.98 \\
\hline
\end{tabular}

\section{Conclusion}

In this research work, one-dimensional $\mathrm{WO}_{3}$ nanorods were synthesized by microwave solvothermal system and used as photocatalyst in the degradation of methyl orange under
UV irradiation. The $\mathrm{WO}_{3}$ nanorods have been successfully synthesized and characterized. $\mathrm{WO}_{3}$ nanorod was found to have a diameter of about $80 \mathrm{~nm}$ and a high aspect ratio of more than 30. Under UV irradiation, photodegradation of methyl orange showed that the photocatalytic activity of $800 \mathrm{~mL}$ solution volume is 3.2 times higher than that of $400 \mathrm{~mL}$ solution volume. UV light screening effect actually affected photocatalytic activity at different initial concentrations of methyl orange. $\mathrm{WO}_{3}$ nanorods can be used in the photodegradation of methyl orange for wastewater treatment. These nanorods have an advantage over commercial $\mathrm{P} 25 \mathrm{TiO}_{2}$ as they are active in presence of UV irradiation.

\section{REFERENCES}

1. E. Forgacs, T. Cserháti and G. Oros, Environ. Int., 30, 953 (2004).

2. V.K. Gupta and Suhas, J. Environ. Manage., 90, 2313 (2009).

3. M. Rafatullah, O. Sulaiman, R. Hashim and A. Ahmad, J. Hazard. Mater., 177, 70 (2010).

4. S. Al-Qaradawi and S.R. Salman, J. Photochem. Photobiol. A, 148, 161 (2002).

5. X.H. Wang, J.G. Li, H. Kamiyama, Y. Moriyoshi and T. Ishigaki, J. Phys. Chem. B, 110, 6804 (2006)

6. F.P. Van Der Zee and S. Villaverde, Water Res., 39, 1425 (2005).

7. A. Mahmood, S. Ali, H. Saleem and T. Hussain, Asian J. Chem., 23, 3875 (2011).

8. S. Malato, J. Blanco, A. Vidal and C. Richter, Appl. Catal. B, 37, 1 (2002).

9. M.R. Hoffmann, S.T. Martin, W. Choi and D.W. Bahnemann, Chem. Rev., 95, 69 (1995)

10. P. Tundo, P. Anastas, D.S.C. Black, J. Breen, T. Collins, S. Memoli, J. Miyamoto, M. Polyakoff and W. Tumas, Pure Appl. Chem., 72, 1207 (2000).

11. H.Y. Xiao, Q.X. Dai, W.S. Li, C.T. Au and X.P. Zhou, J. Mol. Catal. A, 245, 17 (2006)

12. A. Di Paola, G. Marcì, L. Palmisano, M. Schiavello, K. Uosaki, S. Ikeda and B. Ohtani, Phys. Chem. B, 106, 637 (2002).

13. G.T. Brown and J.R. Darwent, J. Phys. Chem., 88, 4955 (1984).

14. C. Santato, M. Odziemkowski, M. Ulmann and J. Augustynski, J. Am. Chem. Soc., 123, 10639 (2001).

15. L. Zhu, Z.-D. Meng, K.-Y. Cho, T. Ghosh and W.-C. Oh, Asian J. Chem., 25, 713 (2013).

16. A.J. Maira, K.L. Yeung, C.Y. Lee, P.L. Yue and C.K. Chan, J. Catal., 192, 185 (2000).

17. Y. Yu and D. Xu, Appl. Catal. B-Environ., 73, 166 (2007).

18. Y.B. Khollam, A.S. Deshpande, A.J. Patil, H.S. Potdar, S.B. Deshpande and S.K. Date, Mater. Chem. Phys., 71, 235 (2001).

19. X. Xu, Y. Bao, C. Song, W. Yang, J. Liu and L. Lin, Micropor. Mesopor. Mater., 75, 173 (2004)

20. H. Yang, C. Huang, X. Li, R. Shi and K. Zhang, Mater. Chem. Phys., 90, 155 (2005)

21. S.N. Frank and A.J. Bard, J. Phys. Chem., 81, 1484 (1977).

22. J. Matos, J. Laine and J.M. Herrmann, J. Catal., 200, 10 (2001).

23. Y. Li, X. Li, J. Li and J. Yin, Water Res., 40, 1119 (2006).

24. Q. Hu, B. Liu, Z. Zhang, M. Song and X. Zhao, J. Wuhan Univ. Technol., 25, 210 (2010)

25. V. Pareek, S. Chong, M. Tadé and A.A. Adesina, Asia Pacific J. Chem. Eng., 3, 171 (2008).

26. W. Choi and M.R. Hoffmann, J. Phys. Chem., 100, 2161 (1996).

27. J. Cao, B. Luo, H. Lin and S. Chen, J. Hazard. Mater., 190, 700 (2011).

28. R. Jiang, H. Zhu, X. Li and L. Xiao, Chem. Eng. J., 152, 537 (2009). 